\title{
García López, O. (2017). Norberto Almandoz (1893-1970) De norte a sur. Historia de un músico en Sevilla. Granada: Editorial Libargo (Música crítica - Musicología), 289 pp. ISBN: 978-84-938812-8-3
}

La recuperación del pasado histórico de la música española necesita trabajos como el que ahora reseñamos en Cuadernos de Investigación Musical, revista siempre preocupada por dar a conocer cualquier novedad en este ámbito de la investigación musical. El protagonista de este libro es Norberto Almandoz, un autor cuya aportación a la música del siglo XX en nuestro país no ha sido suficientemente valorada. Para enmendar esta carencia se publica esta monografía gracias a la benemérita actuación de la editorial Libargo, la cual, desde hace ya algunos años viene publicando títulos de un gran interés histórico-musical. Y vaya por delante nuestra satisfacción pues constituye un motivo para ello que se dé a conocer la trayectoria de un músico singular, como es Norberto Almandoz, el cual desarrolló gran parte de su actividad musical en Sevilla. De esta manera se reivindica asimismo la importancia que jugaron no sólo los grandes centros filarmónicos como Madrid o Barcelona sino también otros centros periféricos.

El gran valor de este libro reside en la detallada visión integral que ofrece del hombre y del compositor, trazada en varias etapas, marcadas en primer lugar por los años de formación en el País Vasco y Cantabria, influenciada por la adscripción al Motu Propio de 1903 y por su interés por la música folclórica vasca gracias a los contactos con José Antonio de Donostia; asimismo la posterior ampliación de estudios en París marcaría profundamente la evolución estilística de nuestro protagonista.

Basándose en todo tipo de información bibliográfica o del vaciado de fuentes primarias, son muy relevantes las conservadas en la Catedral de Sevilla, donde permaneció Almandoz cerca de cuarenta años en calidad de organista y de maestro de capilla), impregnando la vida musical de la ciudad desde su privilegiado puesto. Se ha podido establecer asimismo por primera vez una biografía del autor, caracterizada por el polifacetismo: su labor en Sevilla no se dedicó sólo a la composición de notables obras musicales sino que se vio ampliada por su labor docente, musicológica, interpretativa y de gestión musical, propiciando que la capital hispalense pudiera disfrutar de una envidiable vida operística, por ejemplo.

Apoyándose en la recopilación de fuentes conservadas en el Archivo Vasco de la Música, Archivo musical de la Catedral de Sevilla, el Centro de Documentación y Archivo de la SGAE y la Sala Barbieri de la Biblioteca Nacional de Madrid, García López ha sido 
capaz de enhebrar una completa catalogación de las obras musicales del autor, una labor que se revela como absolutamente indispensable y que es muy de agradecer pues todos los que nos dedicamos al menester musicológico, sabemos del esfuerzo que requiere una tarea titánica como esta. Las fuentes epistolares conservadas, especialmente el intercambio que mantuvo con Manuel de Falla, adquieren asimismo una importancia fundamental para el acercamiento de la personalidad artística de Almandoz.

No rehúye la autora el análisis musical de una selección representativa de obras de Almandoz pero dicho análisis hubiera sido más eficaz si se hubiera recurrido a insertar ejemplos musicales que reforzaran las explicaciones. Asimismo, hubiera sido deseable que el tamaño de la letra fuera mayor pues se dificulta en ocasiones la lectura diáfana de los textos, como es el caso del índice cronológico (a partir de la página 205) o las gráficas de la producción musical de Norberto Almandoz, prácticamente ilegibles. Ello no obsta para recomendar fehacientemente el libro de Olimpia García López, cuya contribución es una buena prueba del buen quehacer de los resultados musicológicos en el Conservatorio de Sevilla y a la cual autora cabe felicitar por este logro que viene a significar ni más ni menos que la recuperación de una figura emblemática de la música española del siglo XX.

\section{Paulino Capdepón Verdú}

Universidad de Castilla-La Mancha Centro de Investigación y Documentación Musical (CIDoM)-Unidad Asociada al CSIC

ORCID iD: https://orcid.org/0000-0001-6509-3496 